\title{
Honoré de Balzac, Philarète Chasles, Charles Rabou, Racconti scuri
}

\section{Marco Stupazzoni}

\section{(2) OpenEdition}

1 Journals

\section{Edizione digitale}

URL: http://journals.openedition.org/studifrancesi/497

DOI: 10.4000/studifrancesi.497

ISSN: 2421-5856

\section{Editore}

Rosenberg \& Sellier

\section{Edizione cartacea}

Data di pubblicazione: 1 aprile 2015

Paginazione: 160-161

ISSN: 0039-2944

\section{Notizia bibliografica digitale}

Marco Stupazzoni, « Honoré de Balzac, Philarète Chasles, Charles Rabou, Racconti scuri », Studi

Francesi [Online], 175 (LIX | I) | 2015, online dal 01 avril 2015, consultato il 18 septembre 2020. URL http://journals.openedition.org/studifrancesi/497 ; DOI : https://doi.org/10.4000/studifrancesi.497

Questo documento è stato generato automaticamente il 18 settembre 2020.

\section{cc) (†) $\odot$}

Studi Francesi è distribuita con Licenza Creative Commons Attribuzione - Non commerciale - Non opere derivate 4.0 Internazionale. 


\title{
Honoré de Balzac, Philarète Chasles, Charles Rabou, Racconti scuri
}

\author{
Marco Stupazzoni
}

\section{NOTIZIA}

HONORÉ DE BALZAC, PHILARÈTE CHASLES, CHARLES RABOU, Racconti scuri, traduzione di Mariagrazia PATURZO, Roma, Aracne, 2013, «Toiles», pp. 472.

1 Frutto della collaborazione di tre (allora) giovani promesse nel campo letterario e giornalistico, la raccolta dei Contes bruns vede per la prima volta la luce nel gennaio del 1832, pubblicata - senza nome d'autore - dagli editori Canel e Guyot. Di Balzac, sono presenti due racconti: il primo (Une Conversation entre onze heures et minuit) che inaugura la raccolta; il secondo, Le Grand d'Espagne, che la conclude; a Ph. Chasles si devono quattro testi: L'CEil sans paupière; Une Bonne Fortune; La Fosse de l'avare e Les Trois Sours; mentre Ch. Rabou è l'autore di altrettanti racconti: Sara la danseuse; Tobias Guarnerius; Les Regrets e Le Ministère public. L'opera, sulla cui copertina risalta l'inquietante doppia immagine satanica di una testa umana rovesciata, ebbe un immediato successo editoriale non soltanto in Francia. Se si considera, infatti, il caso dell'Italia, i Contes bruns ebbero, nel corso della prima metà dell'Ottocento, oltre dieci edizioni, seppur in forma alquanto parziale, a partire dall'ottobre 1833.

2 Questa edizione italiana dell'opera, pubblicata per la prima volta, nel nostro paese, nella sua integralità è inserita nella prestigiosa collana «Toiles» della casa editrice Aracne di Roma, il cui proposito è quello di offrire al vasto pubblico la traduzione, con testo a fronte, di testi francesi così come la pubblicazione di testi tradotti in francese da altre lingue.

3 Ben curata sotto il profilo metodologico e critico da Mariagrazia Paturzo, questo volume dei Racconti scuri è preceduto da un saggio introduttivo della stessa curatrice, nel quale l'A. offre una convincente analisi dei registri tematici e delle tecniche narrative comuni ai dieci racconti. Accanto a motivi riconducibili alla tradizione del 
gothic novel inglese e alla matrice hoffmaniana, sono presenti, nella raccolta, tematiche di chiara matrice sociale che «scuotono la coscienza del lettore portandolo a riflettere su una manifesta crisi collettiva in atto all'epoca» (p. 15). Tra queste, segnaliamo la tematica del parricidio e del matricidio, quella della crisi della famiglia; il tema del fallimento dell'artista o quello, tipicamente balzachiano, ma che tocca in modo trasversale anche Tobias Guarnerius e Les Regrets di Rabou, e La Fosse de l'avare di Chasles, della sempre più marcata influenza del denaro sui destini individuali e sociali dei personaggi. I Racconti scuri, osserva M. Paturzo, «si presentano al lettore di tutte le epoche come un'eterogenea girandola di fuochi d'artificio [...] che gode pure di un'unità legata alla trattazione di certi temi, e al loro rimando ad una società e una letteratura in crisi assiologica» (ibid.). Ed è proprio nel rispecchiamento della letteratura in un contesto globale di crisi che i Contes bruns trovano, ancor oggi, la loro indiscussa modernità.

4 La raccolta completa dei racconti, la cui copia è conforme a quella dell'edizione originale del 1832, è presente alle pp. 18-457; alle pp. 459-461, troviamo l'interessante Postfazione. Il riutilizzo dei "Racconti scuri" balzacchiani, mentre alle pp. 463-466 è presente un capitolo in cui sono forniti alcuni riferimenti biografici relativi ai tre autori. L'utile Nota bibliografica (pp. 467-472) circa le edizioni (integrali e parziali) francesi e italiane dell'opera e i riferimenti critici relativi ai Contes bruns chiude le pagine del volume. 